Article

\title{
Lack of Toxic Interaction between Fusariotoxins in Broiler Chickens Fed throughout Their Life at the Highest Level Tolerated in the European Union
}

\author{
Jean-Paul Metayer ${ }^{1}$, Angelique Travel ${ }^{2}$, Amandine Mika ${ }^{2}$, Jean-Denis Bailly ${ }^{3}{ }^{\circledR}$, Didier Cleva ${ }^{4}$, \\ Cyril Boissieu ${ }^{4}$, Jean Le Guennec ${ }^{5}$, Pascal Froment ${ }^{6}$, Olivier Albaric ${ }^{7}$, Sophie Labrut ${ }^{7}$, \\ Gurvan Lepivert ${ }^{8}$, Eric Marengue ${ }^{8}$, Didier Tardieu ${ }^{9}$ and Philippe Guerre ${ }^{9, *}$ \\ ARVALIS-Institut du Végétal, Station expérimentale, 91720 Boigneville, France \\ ITAVI, Centre INRA Val de Loire, 37380 Nouzilly, France \\ Université de Toulouse, INP, ENVT, Equipe Biosynthèse et Toxicité des Mycotoxines, UMR Toxalim, \\ F-31076 Toulouse, France \\ 4 Chêne Vert Conseil, Z Bellevue II-35220 Chateaubourg, France \\ Finalab, 4 bis rue Th. Botrel, BP 351, 22603 Loudéac CEDEX, France \\ Team Sensor, UMR 7247 INRA/CNRS/Université de Tours/IFCE 37380 Nouzilly, France \\ ONIRIS, Site de la Chantrerie, BP 40706, 44307 Nantes CÉDEX 3, France \\ LABOCEA, 7 rue du Sabot, CS 30054, Zoopole, 22440 Ploufragan, France \\ 9 Université de Toulouse, INP, ENVT, UR Mycotoxicologie, F-31076 Toulouse, France \\ * Correspondence: p.guerre@envt.fr
}

Received: 26 June 2019; Accepted: 23 July 2019; Published: 2 August 2019

check for updates

\begin{abstract}
Fusarium mycotoxins (FUS) occur frequently in poultry diets, and regulatory limits are laid down in several countries. However, the limits were established for exposure to a single mycotoxin, whereas multiple contamination is more realistic, and different studies have demonstrated that it is not possible to predict interactions between mycotoxins. The purpose of this study was thus to compare the toxic effect of deoxynivalenol (DON), fumonisins (FB) and zearalenone (ZON), alone and in combination on broiler chickens, at the maximum tolerated level established by the EU for poultry feed. Experimental corn-soybean diets incorporated ground cultured toxigenic Fusarium strains. One feed was formulated for chickens 0 to 10 days old and another for chickens 11 to 35 days old. The control diets were mycotoxin free, the DON diets contained $5 \mathrm{mg}$ DON $/ \mathrm{kg}$, the FB diet contained $20 \mathrm{mg}$ $\mathrm{FB} 1+\mathrm{FB} 2 / \mathrm{kg}$, and the ZON diet contained $0.5 \mathrm{mg} Z \mathrm{ZON} / \mathrm{kg}$. The DONFBZON diet contained 5, 20, and $0.5 \mathrm{mg} / \mathrm{kg}$ of DON, FB1 + FB2, and ZON, respectively. Diets were distributed ad libitum to 70 broilers (male Ross PM3) separated into five groups of 14 chickens each reared in individual cages from one to 35 days of age. On day 35 , after a starvation period of $8 \mathrm{~h}$, a blood sample was collected, and all the animals were killed and autopsied. No difference between groups that could be attributed to FUS was observed in performances, the relative weight of organs, biochemistry, histopathology, intestinal morphometry, variables of oxidative damage, and markers of testicle toxicity. A significant increase in sphinganine and in the sphinganine to sphingosine ratio was observed in broilers fed FB. Taken together, these results suggest that the regulatory guidelines established for single contamination of broiler chickens fed with DON, FB, and ZON can also be used in the case of multiple contamination with these toxins.
\end{abstract}

Keywords: feed; broilers; deoxynivalenol; fumonisins; zearalenone; interactions 
Key Contribution: This study compares the toxic effect of deoxynivalenol (DON), fumonisins (FB) and zearalenone ( $\mathrm{ZON})$, alone and in combination on broiler chickens, at the maximum tolerated level established by the EU for poultry feed. The lack of toxic interactions in the variables measured in this assay suggests that the regulatory guidelines established for single contamination of broiler chickens fed can also be used in the case of multiple contaminations with DON, FB, and ZON.

\section{Introduction}

The worldwide contamination of raw materials with mycotoxins is a safety concern in both humans and in animal species, including poultry. In Europe, the occurrence of aflatoxins and ochratoxins is relatively low. The co-occurrence of mycotoxins produced by Fusarium (Fusariotoxins, FUS) in avian feed is the most frequent [1-4]. Among FUS, four compounds are subject to international and European guidelines on their maximum tolerated levels in avian feed. These toxins are members of group A and $\mathrm{B}$ trichothecenes, $\mathrm{T}-2$ toxin (T-2) and deoxynivalenol (DON) respectively, the myco-estrogenic zearalenone (ZON), and fumonisins $\mathrm{B} 1$ and $\mathrm{B} 2$ (FB1 and FB2), belonging to group $\mathrm{B}$ of fumonisins (FB). Among the FUS with regulatory limits, DON, FB and ZON occur the most frequently in poultry diets, whereas T-2 is less frequent in Europe [2,5,6].

Although the effects of mycotoxins on health have been intensively studied in different poultry species, most information available on toxicity was obtained using exposure to a single mycotoxin, and most studies involved a high level of exposure. By contrast, combined effects of low levels/doses of toxins are more likely but less well understood [7-11]. Most studies on the combined effects of mycotoxins were done using aflatoxin B1 in association with FUS [12-17]. Only very few studies have investigated the combined effects of FUS in poultry. One trial investigated the effects of high doses of FB1 and DON on broiler chicks from hatching up to 21 days of age [18]. In this assay, $300 \mathrm{mg} \mathrm{FB} 1 / \mathrm{kg}$ feed combined with $15 \mathrm{mg}$ DON/kg feed, had some synergic toxic effects on serum biochemistry (increases in the activity of aspartate aminotransferase, lactate dehydrogenase, and gamma glutamyl transferase), and a less than additive effect on body weight gain (BWG), whereas an antagonistic effect was observed on the relative weight (RW) of the heart. Another study, also using FB1 and DON, was conducted on chickens exposed to a subclinical dose of Eimeria spp., responsible for coccidiosis [19]. The conclusion of that study was that interactions between DON and FB1 depended to a large extent on the endpoint assessed, with three endpoints reporting antagonism, nine additivity, and two synergism. Another trial investigated the combined effects of FB and ZON on nutrient digestibility in female broilers [20]. In this assay, the effect of ZON ( 0 vs. $1 \mathrm{mg} / \mathrm{kg}$ feed) in the presence of different concentrations of FB ( 3.15 and $5.5 \mathrm{mg} / \mathrm{kg}$ feed) was investigated. The main result was that nutrient digestibility may be improved by dietary ZON at a level of $1 \mathrm{mg} / \mathrm{kg}$ but was not affected by different levels of FB.

Taken together, these results suggest that it is not possible to predict interactions between FUS, as already reported for all other mycotoxins $[8,21]$. Complementary data were thus required to draw conclusions concerning the maximum tolerated doses established for single contamination in the case of multiple contaminations. The purpose of this study was to compare the toxic effects of DON, FB, and $\mathrm{ZON}$, alone and in combination, at the maximum tolerated level defined for poultry feed by the EU [22]. The study was conducted on broiler chicks from hatching until 35 days of age to maximize the animal's exposure to the toxins. We investigated the effects on performance, organ weight, and histopathology, these being the parameters most frequently used to reveal deleterious effects, but also on some more specific markers of toxicity such as intestinal morphometry and the number of goblet cells, oxidative damage, sphingolipid metabolism and male reproductive toxicity. 


\section{Results}

\subsection{Diets and Performances}

Table 1 shows the expected and measured levels of FUS in the diets. Although traces of DON, FB, and $\mathrm{ZON}$ were found in the control diets, their levels were always $<100 \mu \mathrm{g} / \mathrm{kg}$ and were considered not significant. Measured concentrations of DON, FB, and ZON in the contaminated diets differed between $10 \%$ and $20 \%$ from the expected levels. The biggest difference was found for DON in the DONFBZON diet. In all the diets, no unexpected FUS, other than DON, FB, and ZON, were detected or were $<20 \mu \mathrm{g} / \mathrm{kg}$. All other mycotoxins were below the limit of quantitation.

Table 1. Mycotoxin levels in the experimental diets fed to broiler chickens from 0 to 35 days of age.

\begin{tabular}{|c|c|c|c|c|c|}
\hline \multirow[t]{2}{*}{ Mycotoxins } & \multicolumn{5}{|c|}{ Experimental Diets } \\
\hline & Control $^{1}$ & DON $^{1}$ & FB $^{1}$ & $\mathrm{ZON}^{1}$ & DONFBZON $^{1}$ \\
\hline \multicolumn{6}{|l|}{ Deoxynivalenol } \\
\hline Expected & 0 & 5000 & 0 & 0 & 5000 \\
\hline Measured 0-10 & 50 & 4570 & 60 & 55 & 3820 \\
\hline Measured 11-35 & 50 & 4720 & 65 & 50 & 4170 \\
\hline \multicolumn{6}{|l|}{ Fumonisins } \\
\hline Expected $^{2}$ & 0 & 0 & 20,000 & 0 & 20,000 \\
\hline Measured 0-10 3 & $25 /<10 /<10$ & $30 /<10 /<10$ & $19,500 / 1600 / 2000$ & $70 / 10 / 15$ & $17,600 / 1440 / 2050$ \\
\hline Measured 11-35 3 & $35 /<10 /<10$ & $30 /<10 /<10$ & $21,000 / 2130 / 2300$ & $90 / 15 / 20$ & $17,700 / 1530 / 2030$ \\
\hline \multicolumn{6}{|l|}{ Zearalenone } \\
\hline Expected & 0 & 0 & 0 & 500 & 500 \\
\hline Measured 0-10 & 35 & 40 & 35 & 465 & 415 \\
\hline Measured 11-35 & 25 & 25 & 25 & 480 & 430 \\
\hline
\end{tabular}

${ }^{1}$ As described in Material and Methods, 10 experimental diets were formulated to provide respective total protein and metabolizable energy of $22 \%$ and $2880 \mathrm{kcal} / \mathrm{kg}$ for chickens from 0 to 10 days of age and $19.5 \%$ and $3050 \mathrm{kcal} / \mathrm{kg}$ for chickens from 11 to 35 days of age. Expected and measured concentrations of fusariotoxins $(\mu \mathrm{g} / \mathrm{kg})$ in the diets contaminated by deoxynivalenol alone (DON), fumonisins alone (FB), zearalenone alone (ZON) and a mixture of the three toxins (DONFBZON). ${ }^{2}$ Sum of FB1 + FB2. ${ }^{3}$ Concentrations of fumonisin B1 (FB1), fumonisin B2 (FB2) and fumonisin B3 (FB3), respectively.

Neither mortality nor any signs of mycotoxicosis were observed in any of the chickens during the 35-days study. The effects of feeding FUS on performances at the two ages are detailed in Table 2. From 0 to 10 days, no differences among groups were observed in body weight (BW), feed consumption (FC), daily weight gain (DWG), and feed conversion ratio (FCR). By contrast, a significant increase in FC was observed in chickens fed the ZON and DONFBZON diets from 11 to 35 days, but had no consequence for BW and FCR. Over the entire period (0 to 35 days), the only significant difference observed among the groups was in FC, but no group differed significantly from the control group (data not shown). 
Table 2. Effects of fusariotoxins on performances and relative organ weights in broiler chickens ${ }^{1}$.

\begin{tabular}{|c|c|c|c|c|c|}
\hline Variable $^{3}$ & Control $^{2}$ & $\mathrm{DON}^{2}$ & FB $^{2}$ & $\mathrm{ZON}^{2}$ & DONFBZON $^{2}$ \\
\hline BW (D11) & $257 \pm 35$ & $248 \pm 31$ & $265 \pm 37$ & $263 \pm 34$ & $273 \pm 24$ \\
\hline BW (D35) & $2248 \pm 134$ & $2235 \pm 19$ & $2358 \pm 249$ & $2395 \pm 214$ & $2404 \pm 143$ \\
\hline $\mathrm{FC}(0-10)$ & $248 \pm 37$ & $247 \pm 37$ & $265 \pm 42$ & $265 \pm 39$ & $271 \pm 27$ \\
\hline FC (11-35)* & $3058 \pm 193^{a}$ & $3038 \pm 236^{a}$ & $3232 \pm 299^{a, b}$ & $3303 \pm 271^{b}$ & $3289 \pm 180^{b}$ \\
\hline DWG (0-10) & $19.2 \pm 3.3$ & $18.5 \pm 2.8$ & $20 \pm 3.4$ & $19.8 \pm 3.2$ & $20.7 \pm 2.1$ \\
\hline DWG (11-35) & $83 \pm 4.8$ & $82.8 \pm 7$ & $87.2 \pm 9.3$ & $88.8 \pm 7.9$ & $88.8 \pm 5.5$ \\
\hline FCR $(0-10)$ & $1.18 \pm 0.05$ & $1.22 \pm 0.05$ & $1.21 \pm 0.05$ & $1.22 \pm 0.06$ & $1.19 \pm 0.03$ \\
\hline FCR (11-35) & $1.54 \pm 0.03$ & $1.53 \pm 0.03$ & $1.55 \pm 0.04$ & $1.55 \pm 0.04$ & $1.54 \pm 0.04$ \\
\hline Liver RW * & $1.99 \pm 0.19^{a, b}$ & $1.87 \pm 0.19^{b}$ & $1.92 \pm 0.16^{b}$ & $2.09 \pm 0.18^{a}$ & $1.9 \pm 0.12^{b}$ \\
\hline Kidney RW & $0.61 \pm 0.06$ & $0.62 \pm 0.04$ & $0.62 \pm 0.06$ & $0.6 \pm 0.05$ & $0.62 \pm 0.06$ \\
\hline Intestine RW & $2.1 \pm 0.40$ & $2.1 \pm 0.25$ & $2.11 \pm 0.2$ & $2.06 \pm 0.23$ & $2.01 \pm 0.22$ \\
\hline Caecum RW & $0.27 \pm 0.04$ & $0.26 \pm 0.05$ & $0.28 \pm 0.05$ & $0.26 \pm 0.04$ & $0.26 \pm 0.04$ \\
\hline Gizzard RW & $1.07 \pm 0.23$ & $1.1 \pm 0.17$ & $1.22 \pm 0.26$ & $1.05 \pm 0.12$ & $1.05 \pm 0.22$ \\
\hline Hearth RW & $0.69 \pm 0.08$ & $0.71 \pm 0.07$ & $0.64 \pm 0.07$ & $0.7 \pm 0.06$ & $0.69 \pm 0.08$ \\
\hline Tonsil RW & $0.06 \pm 0.01$ & $0.05 \pm 0.01$ & $0.06 \pm 0.01$ & $0.05 \pm 0.01$ & $0.06 \pm 0.01$ \\
\hline Bursa RW & $0.22 \pm 0.03$ & $0.22 \pm 0.05$ & $0.23 \pm 0.06$ & $0.20 \pm 0.03$ & $0.19 \pm 0.05$ \\
\hline
\end{tabular}

${ }^{1}$ Values were obtained from 14 animals per group and are expressed as mean $\pm \mathrm{SD}$. ANOVA was performed to compare groups. When a significant difference was observed $\left({ }^{*} p<0.05\right)$, means were compared (Kruskall-Wallis). Different letters in the same row identify statistically different groups $(p<0.05) .{ }^{2}$ Experimental diets were formulated as described in Material and Methods to reach a final concentration of $5 \mathrm{mg}$ DON $/ \mathrm{kg} \operatorname{diet}(\mathrm{DON}), 20 \mathrm{mg}$ FB1 + FB2/ $/ \mathrm{kg} \operatorname{diet}(\mathrm{FB}), 0.5 \mathrm{mg} \mathrm{ZON} / \mathrm{kg}$ diet and $5 \mathrm{mg} \mathrm{DON}+20 \mathrm{mg}$ FB1 + FB2 + $0.5 \mathrm{mg}$ ZON $/ \mathrm{kg} \operatorname{diet}(\mathrm{DONFBZON})$. The control diet was free of mycotoxins. ${ }^{3}$ Results are expressed in the following units: Feed consumption (FC), g; daily weight gain (DWG), g; feed conversion ratio (FCR) calculated from D0 to D10 and from D11 to D35. Relative organs weights (RW) measured on D35 after killing.

\subsection{Relative Organ Weights and Histopathology}

Although some signs of runny noses, puddle hearts, and signs of reactivity in the caeca tonsils were found in some chickens, these signs were not more marked in one group than in another. The effects of FUS on the relative weights (RW) of liver, kidney, intestine, caecum, gizzard, and hearth are shown in Table 2. Although some differences in the RW of the liver were found among groups, no group differed from the control group. No significant difference in the RW of pancreas, spleen, proventriculus, duodenum, jejunum, ileum, caeca tonsils, and Fabricius bursa was observed among groups (Table 2). The color of the liver and caeca tonsils did not differ among groups.

Histopathological examination of the hepatic and renal samples revealed discrete non-specific inflammatory lesions with no difference in frequency or intensity among groups. Lymphoid hyperplasia with signs of typhlitis was observed in the caeca mucosa. These lesions varied greatly depending on the section examined and were not more frequent in one group than in another. Characterization of intestinal morphometry of duodenum, jejunum, and ileum revealed no significant differences in the size of the villus and crypts in the duodenum and ileum among groups whereas a small increase in crypt depth of the jejunum was observed in broilers fed the diet containing FUS (Table 3). Moreover, no significant difference in the surface area and the villus to crypt ratio of the duodenum and ileum was found among groups (data not shown). By contrast, in the jejunum, the surface area of the crypt increased in broilers fed FUS whereas the villus to crypt ratio decreased and the surface area of the villus was not affected (Table 3). No significant difference in the number of goblet cells in the duodenum, jejunum, and ileum was found among groups. 
Table 3. Effects of fusariotoxins on the density and morphometry of segments of the small intestinal in broiler chickens ${ }^{1}$.

\begin{tabular}{|c|c|c|c|c|c|}
\hline Variable $^{3}$ & Control $^{2}$ & $\mathrm{DON}^{2}$ & FB $^{2}$ & $\mathrm{ZON}^{2}$ & DONFBZON $^{2}$ \\
\hline \multicolumn{6}{|l|}{ Density } \\
\hline Duodenum & $0.35 \pm 0.03$ & $0.36 \pm 0.04$ & $0.37 \pm 0.04$ & $0.38 \pm 0.05$ & $0.36 \pm 0.05$ \\
\hline Jejunum & $0.32 \pm 0.04$ & $0.31 \pm 0.03$ & $0.31 \pm 0.03$ & $0.32 \pm 0.06$ & $0.33 \pm 0.05$ \\
\hline Ileum & $0.24 \pm 0.03$ & $0.22 \pm 0.03$ & $0.24 \pm 0.04$ & $0.23 \pm 0.05$ & $0.23 \pm 0.04$ \\
\hline \multicolumn{6}{|l|}{ Duodenum } \\
\hline Villus height & $1.28 \pm 0.14$ & $1.29 \pm 0.13$ & $1.29 \pm 0.14$ & $1.43 \pm 0.2$ & $1.3 \pm 0.14$ \\
\hline Villus width & $684 \pm 67$ & $625 \pm 82$ & $708 \pm 127$ & $683 \pm 149$ & $658 \pm 103$ \\
\hline Crypt depth & $141 \pm 12$ & $138 \pm 12$ & $142 \pm 12$ & $147 \pm 9$ & $143 \pm 12$ \\
\hline Crypt width & $47 \pm 3$ & $45 \pm 3$ & $46 \pm 3$ & $46 \pm 4$ & $44 \pm 4$ \\
\hline Goblet cells & $107 \pm 18$ & $123 \pm 18$ & $110 \pm 18$ & $113 \pm 17$ & $123 \pm 90$ \\
\hline \multicolumn{6}{|l|}{ Jejunum } \\
\hline Villus height & $1.15 \pm 0.12$ & $1.2 \pm 0.16$ & $1.22 \pm 0.11$ & $1.14 \pm 0.15$ & $1.16 \pm 0.11$ \\
\hline Villus width & $659 \pm 134$ & $658 \pm 151$ & $676 \pm 126$ & $738 \pm 159$ & $679 \pm 62$ \\
\hline Villus area & $756 \pm 151$ & $801 \pm 236$ & $831 \pm 192$ & $838 \pm 208$ & $786 \pm 108$ \\
\hline Crypt depth * & $99 \pm 7^{a}$ & $130 \pm 18^{b}$ & $145 \pm 14^{c}$ & $145 \pm 19^{c}$ & $152 \pm 12^{c}$ \\
\hline Crypt width & $40 \pm 3$ & $44 \pm 3$ & $41 \pm 5$ & $42 \pm 4$ & $44 \pm 4$ \\
\hline Crypt area * & $4 \pm 1^{a}$ & $6 \pm 1^{b}$ & $6 \pm 1^{b}$ & $6 \pm 1^{b}$ & $7 \pm 1^{b}$ \\
\hline Villus/Crypt * & $11.65 \pm 0.82^{a}$ & $9.25 \pm 1.28^{b}$ & $8.46 \pm 0.82^{b, c}$ & $7.84 \pm 1.03^{c}$ & $7.64 \pm 0.60^{c}$ \\
\hline Goblet cells & $128 \pm 23$ & $133 \pm 24$ & $131 \pm 23$ & $127 \pm 27$ & $141 \pm 22$ \\
\hline \multicolumn{6}{|l|}{ Ileum } \\
\hline Villus height & $0.787 \pm 0.094$ & $0.847 \pm 0.089$ & $0.831 \pm 0.119$ & $0.808 \pm 0.157$ & $0.903 \pm 0.181$ \\
\hline Villus width & $428 \pm 44$ & $402 \pm 43$ & $407 \pm 71$ & $438 \pm 67$ & $459 \pm 114$ \\
\hline Crypt depth & $141 \pm 13$ & $139 \pm 11$ & $139 \pm 16$ & $140 \pm 14$ & $145 \pm 15$ \\
\hline Crypt width & $44 \pm 4$ & $45 \pm 3$ & $45 \pm 3$ & $43 \pm 4$ & $45 \pm 2$ \\
\hline Goblet cells & $193 \pm 22$ & $192 \pm 26$ & $186 \pm 34$ & $182 \pm 38$ & $194 \pm 35$ \\
\hline
\end{tabular}

${ }^{1}$ Values were obtained from 14 animals per group and are expressed as mean \pm SD. ANOVA was performed to compare groups. When a significant difference was observed $\left({ }^{*} p<0.05\right)$, means were compared (Kruskall-Wallis). Different letters in the same row identify statistically different groups $(p<0.05) .{ }^{2}$ Experimental diets were formulated as described in Material and Methods to reach a final concentration of $5 \mathrm{mg}$ DON/kg diet (DON), $20 \mathrm{mg}$ FB1 + FB2 $/ \mathrm{kg}$ diet (FB), $0.5 \mathrm{mg} \mathrm{ZON} / \mathrm{kg}$ diet and $5 \mathrm{mg}$ DON $+20 \mathrm{mg}$ FB1 + FB2 + $0.5 \mathrm{mg}$ ZON $/ \mathrm{kg}$ diet (DONFBZON). The control diet was free of mycotoxins. ${ }^{3}$ Results are expressed in the following units: Villus height, mm; villus width, crypt depth, crypt width, $\mu \mathrm{m}$; villus surface area, crypt surface area, $\mathrm{mm}^{2} \times 1000$; goblet cells, number of cells $/ 0.02 \mathrm{~mm}^{2}$.

\subsection{Serum Biochemistry and Hematology}

The effect of FUS on biochemistry and hematology are presented in Table 4. No statistical difference in proteins, cholesterol, $\mathrm{IgA}$ and $\mathrm{Hb}$ concentrations was found among groups. In the same way, no effect was observed on LDH, ALP, and ALT activities or on the number of erythrocytes and leucocytes. Only a small but significant increase in the concentration of uric acid was observed in chickens fed with $\mathrm{ZON}$ alone. 
Table 4. Effects of fusariotoxins on biochemistry and hematology in broiler chickens ${ }^{1}$.

\begin{tabular}{cccccc}
\hline Variable $^{3}$ & Control $^{\mathbf{2}}$ & DON $^{\mathbf{2}}$ & FB $^{2}$ & ZON $^{\mathbf{2}}$ & DONFBZON $^{2}$ \\
\hline Proteins & $30.9 \pm 4.5$ & $30.5 \pm 2.5$ & $30.9 \pm 2.9$ & $32.4 \pm 9$ & $31.6 \pm 4.3$ \\
Cholesterol & $1.51 \pm 0.15$ & $1.55 \pm 0.19$ & $1.5 \pm 0.12$ & $1.51 \pm 0.21$ & $1.45 \pm 0.11$ \\
Uric acid $^{*}$ & $40.9 \pm 13.2^{\mathrm{a}}$ & $40.1 \pm 9.2^{\mathrm{a}}$ & $47.1 \pm 18.3 \mathrm{a}, \mathrm{b}$ & $59.9 \pm 16.3 \mathrm{~b}$ & $50.5 \pm 11.6^{\mathrm{a}, \mathrm{b}}$ \\
LDH & $3450 \pm 952$ & $2779 \pm 762$ & $3241 \pm 690$ & $3598 \pm 1635$ & $3110 \pm 842$ \\
ALP & $2133 \pm 925$ & $1706 \pm 499$ & $2049 \pm 816$ & $2,180 \pm 953$ & $1664 \pm 449$ \\
ALT & $5.71 \pm 3.5$ & $5.71 \pm 3.2$ & $6.29 \pm 4.2$ & $4.43 \pm 3.44$ & $5.21 \pm 3.51$ \\
IgA & $221 \pm 54$ & $176 \pm 73$ & $171 \pm 49$ & $163 \pm 52$ & $194 \pm 59$ \\
Hb & $13.5 \pm 1.1$ & $13.7 \pm 0.7$ & $13.7 \pm 0.9$ & $13.3 \pm 1.2$ & $13.7 \pm 1.1$ \\
Erythrocytes & $2.42 \pm 0.21$ & $2.51 \pm 0.2$ & $2.47 \pm 0.26$ & $2.4 \pm 0.25$ & $2.51 \pm 0.22$ \\
Leucocytes & $20.3 \pm 2.2$ & $19.5 \pm 1.4$ & $19.2 \pm 1.4$ & $19.4 \pm 1.9$ & $20 \pm 1.7$ \\
\hline
\end{tabular}

${ }^{1}$ Values were obtained from 14 animals per group aged 35 days and are expressed as mean \pm SD. One-way ANOVA was performed to compare groups. When a significant difference was observed $\left({ }^{*} p<0.05\right)$, means were compared (Kruskall-Wallis). Different letters in the same row identify statistically different groups $(p<0.05) .{ }^{2}$ Experimental diets were formulated as described in Materials and Methods to reach a final concentration of $5 \mathrm{mg}$ DON/kg diet (DON), $20 \mathrm{mg}$ FB1 + FB2/kg diet (FB), $0.5 \mathrm{mg} \mathrm{ZON} / \mathrm{kg}$ diet and $5 \mathrm{mg}$ DON + $20 \mathrm{mg}$ FB1 + FB2 + $0.5 \mathrm{mg}$ ZON/kg diet (DONFBZON). The control diet was free of mycotoxins. ${ }^{3}$ Results are expressed in the following units: Proteins, $\mathrm{g} / \mathrm{L}$; cholesterol, $\mathrm{mmol} / \mathrm{L}$, uric acid, $\mathrm{mmol} / \mathrm{L}$; lactate dehydrogenase (LDH), UI/L; alkaline phosphatase (ALP), UI/L; alanine aminotransferase (ALT), UI/L; immunoglobulin A(IgA), $\mu \mathrm{g} / \mathrm{L})$, hemoglobin $(\mathrm{Hb}), \mathrm{mg} / \mathrm{L}$; erythrocytes and leucocytes, $10^{3}$ number of cells $/ \mathrm{mL}$.

\subsection{Oxidative Markers and Antioxidant Enzyme Activity in Plasma and Liver}

Different variables were investigated to identify oxidative damage to broiler chickens (Table 5). MDA and TGlu contents in plasma, and MDA, TGlu, and GSSG contents in the liver remained unchanged after exposure to FUS. The GSH/GSSG ratio in the liver was also unaffected by the toxins (data not shown). Investigation of the activities of most of the enzymes involved in defense against oxidative damage, SOD, CAT, GsPx, and GsRed, both in plasma and liver, failed to reveal any effect of the FUS, alone or in association.

Table 5. Effects of fusariotoxins on oxidative stress variables in broiler chickens ${ }^{1}$.

\begin{tabular}{|c|c|c|c|c|c|}
\hline Variable $^{3}$ & Control $^{2}$ & $\mathrm{DON}^{2}$ & FB $^{2}$ & $\mathrm{ZON}^{2}$ & DONFBZON $^{2}$ \\
\hline \multicolumn{6}{|l|}{ Plasma } \\
\hline MDA & $683 \pm 184$ & $734 \pm 233$ & $676 \pm 174$ & $600 \pm 213$ & $608 \pm 220$ \\
\hline TGs & $7.8 \pm 1.4$ & $8.1 \pm 2.6$ & $6.9 \pm 1.8$ & $6.8 \pm 2.2$ & $6.6 \pm 1.7$ \\
\hline SOD & $136 \pm 28$ & $128 \pm 47$ & $136 \pm 52$ & $134 \pm 63$ & $109 \pm 52$ \\
\hline CAT & $5.5 \pm 1.3$ & $5.4 \pm 1.2$ & $4.8 \pm 0.5$ & $5.2 \pm 0.8$ & $5.1 \pm 1.1$ \\
\hline GsPx & $144 \pm 44$ & $132 \pm 22$ & $138 \pm 20$ & $132 \pm 19$ & $137 \pm 26$ \\
\hline GsRed & $7.9 \pm 3.6$ & $9.3 \pm 3.1$ & $10.1 \pm 3.2$ & $8.8 \pm 3$ & $8.8 \pm 3.3$ \\
\hline \multicolumn{6}{|l|}{ Liver } \\
\hline MDA & $13.3 \pm 5.7$ & $11 \pm 4.8$ & $11.5 \pm 6.4$ & $11.7 \pm 5.1$ & $13.2 \pm 6$ \\
\hline TGs & $22.3 \pm 5.5$ & $24.8 \pm 8.4$ & $24.6 \pm 6.1$ & $24.8 \pm 8.1$ & $21.5 \pm 5.7$ \\
\hline GSSG & $3.8 \pm 1.2$ & $4.7 \pm 2.2$ & $4.2 \pm 2.2$ & $4.9 \pm 2.2$ & $3.4 \pm 1.3$ \\
\hline SOD & $20.4 \pm 5.3$ & $18.1 \pm 8.1$ & $18.5 \pm 6.7$ & $18.3 \pm 8.3$ & $18.6 \pm 4.6$ \\
\hline CAT & $16.6 \pm 5.4$ & $20 \pm 5.6$ & $20.9 \pm 9.6$ & $17.1 \pm 8$ & $16.7 \pm 6.3$ \\
\hline GPx & $37.9 \pm 8.7$ & $39.2 \pm 3.6$ & $39.4 \pm 7.5$ & $39 \pm 4.9$ & $37.9 \pm 4.1$ \\
\hline GRed & $14 \pm 2.2$ & $15.3 \pm 2.1$ & $15.3 \pm 3.8$ & $13.2 \pm 2.6$ & $14.1 \pm 3.3$ \\
\hline
\end{tabular}

1 Values were obtained from 14 animals per group and are expressed as mean \pm SD. One-way ANOVA was performed to compare groups. No significant difference among groups was observed $(p>0.05)$. ${ }^{2}$ Five experimental diets were formulated as described in Material and Methods to reach a final concentration of $5 \mathrm{mg} D O N / \mathrm{kg}$ diet (DON), $20 \mathrm{mg}$ FB1 + FB2/kg diet (FB), $0.5 \mathrm{mg}$ ZON $/ \mathrm{kg}$ diet and $5 \mathrm{mg} \mathrm{DON}+20 \mathrm{mg}$ FB1 + FB2 + $0.5 \mathrm{mg}$ ZON $/ \mathrm{kg}$ diet (DONFBZON). The control diet was free of mycotoxins. ${ }^{3}$ Results are expressed per L of plasma or per mg of $S 9$ liver proteins in the following units: Malondialdehyde (MDA), nmol; total glutathione (TGs), $\mu$ mol GSSG; oxidized glutathione (GSSG), $\mu \mathrm{mol}$; superoxide dismutase (SOD), U/min; catalase (CAT), $\mu$ g of formaldehyde $\left(\mathrm{CH}_{2} \mathrm{O}\right) / \mathrm{min}$; glutathione peroxidase (GPx), $\mu \mathrm{mol}$ nicotinamide adenine dinucleotide phosphate (NADPH)/min; glutathione reductase (GRed), $\mu \mathrm{mol} \mathrm{NADPH/min}$. 


\subsection{Testis Toxicity}

The weight of the testis was similar in all the groups but the ZON group presented a $25 \%$ increase in weight compared to the control group (Table 6). The diameter of the seminiferous tubule in the ZON group was also $17 \%$ larger than in the controls, whereas a $21 \%$ decrease was observed in the DONFBZON group. Cell death observed by ISEL staining failed to reveal any significant difference among groups (data not shown). The activity of the cleaved caspase 3 was similar in the five groups (Table 6).

Table 6. Effects of fusariotoxins on testes in broiler chickens ${ }^{1}$.

\begin{tabular}{cccccc}
\hline Variable $^{3}$ & Control $^{\mathbf{2}}$ & DON $^{2}$ & FB $^{2}$ & ZON $^{2}$ & DONFBZON $^{2}$ \\
\hline Testis & $207 \pm 14$ & $244 \pm 25$ & $148 \pm 17$ & $263 \pm 21$ & $230 \pm 16$ \\
STD & $56.5 \pm 1.6$ & $54.7 \pm 1$ & $52.1 \pm 0.7$ & $66.5 \pm 1.5$ & $44.8 \pm 0.7$ \\
Cleaved & $4.33 \pm 0.46$ & $4.16 \pm 0.68$ & $2.48 \pm 0.36$ & $3.12 \pm 0.47$ & $3.52 \pm 0.68$ \\
caspase $^{3}$ & & & & \\
DAZL $^{*}$ & $0.28 \pm 0.02^{\mathrm{a}}$ & $2.24 \pm 0.96^{\mathrm{b}}$ & $8.18 \pm 2.78^{\mathrm{c}}$ & $1.02 \pm 0.24^{\mathrm{b}}$ & $0.89 \pm 0.42^{\mathrm{b}}$ \\
PCNA $^{*}$ & $1.19 \pm 0.11^{\mathrm{a}}$ & $2.49 \pm 0.45^{\mathrm{a}}$ & $4.66 \pm 0.70^{\mathrm{b}}$ & $2.13 \pm 0.55^{\mathrm{a}}$ & $1.57 \pm 0.33^{\mathrm{a}}$ \\
IFN- $\gamma$ & $0.58 \pm 0.12$ & $0.92 \pm 0.07$ & $0.49 \pm 0.16$ & $0.46 \pm 0.12$ & $0.25 \pm 0.04$ \\
Il1 & $4.59 \pm 2.70$ & $6.71 \pm 3.50$ & $4.84 \pm 2.18$ & $3.18 \pm 1.69$ & $2.23 \pm 0.57$ \\
TAC & $7.30 \pm 1.90$ & $9.95 \pm 2.76$ & $9.63 \pm 1.71$ & $14.51 \pm 3.88$ & $9.61 \pm 1.33$ \\
CAT & $14.68 \pm 4.50$ & $17.34 \pm 4.91$ & $12.79 \pm 0.87$ & $11.63 \pm 1.73$ & $5.55 \pm 1.02$ \\
cAMP & $219 \pm 48$ & $594 \pm 224$ & $1447 \pm 335$ & $1094 \pm 325$ & $1321 \pm 385$ \\
Testosterone & $396 \pm 199$ & $288 \pm 105$ & $443 \pm 150$ & $402 \pm 156$ & $448 \pm 177$ \\
\hline
\end{tabular}

${ }^{1}$ Values are expressed as mean \pm SEM. One-way ANOVA was performed to compare groups. When a significant difference was observed $\left.{ }^{*} p<0.05\right)$, means were compared (Kruskall-Wallis). Different letters in the same row identify statistically different groups $(p<0.05) .{ }^{2}$ Experimental diets were formulated as described in Material and Methods to reach a final concentration of $5 \mathrm{mg}$ DON $/ \mathrm{kg} \operatorname{diet}(\mathrm{DON}) .20 \mathrm{mg} \mathrm{FB} 1+$ FB2 $/ \mathrm{kg} \operatorname{diet}(\mathrm{FB}) .0 .5 \mathrm{mg}$ $\mathrm{ZON} / \mathrm{kg}$ diet and $5 \mathrm{mg}$ DON $+20 \mathrm{mg}$ FB1 + FB2 + $0.5 \mathrm{mg}$ ZON $/ \mathrm{kg}$ diet (DONFBZON). The control diet was free of mycotoxins. ${ }^{3}$ Results are expressed in the following units: Testis weight, $\mathrm{mg}$; seminiferous tubules diameter, $\mu \mathrm{m}$; caspase 3 activity, relative luminescence units (RLU)/mg protein; deleted in azoospermia-like (DAZL), ng/mg protein; proliferating cell nuclear antigen (PCNA), ng/mg protein; interferon gamma (IFN- $\gamma$ ), pg/mg protein; interleukin 1 beta (Il1 $\beta), \mathrm{pg} / \mu \mathrm{g}$ proteins; total antioxidant capacity (TAC), trolox equivalent antioxidant capacity/mg proteins; catalase (CAT) activity, in $\mathrm{pmol} / \mathrm{min} / \mathrm{mL} / \mu \mathrm{g}$ proteins; cAMP, $\mu$ Molar $/ \mathrm{mg}$ proteins; testosterone, $\mathrm{ng} / \mu \mathrm{g}$ proteins.

As revealed by VASA staining, germ cells were present in the testis (Figure 1). The number of immature germ cells estimated by intra-testis Dazl content was higher in the FB group than in the other groups. This increase was associated with higher PCNA content, a marker of cell proliferation, in the FB group.

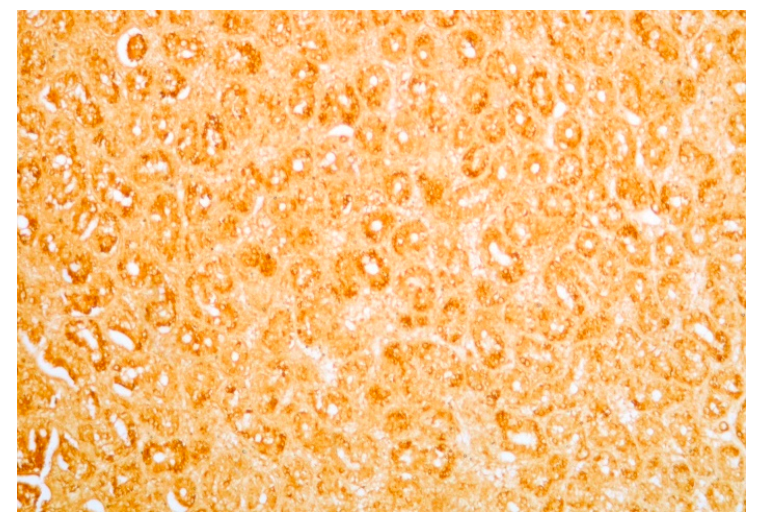

(A)

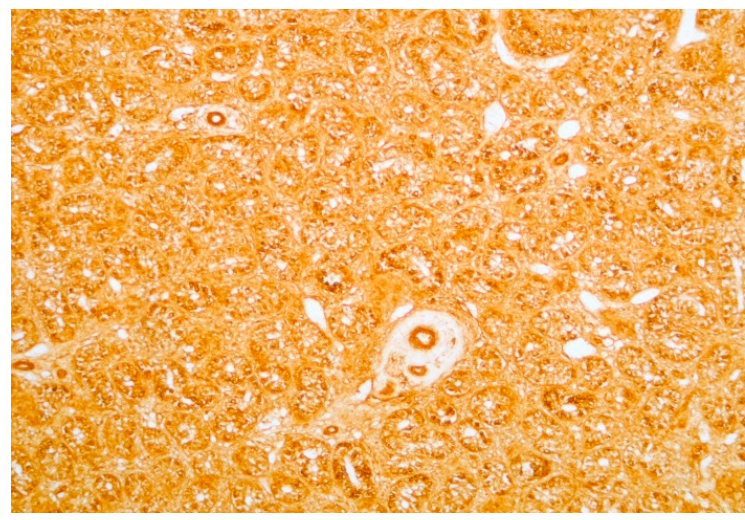

(B)

Figure 1. Cont. 


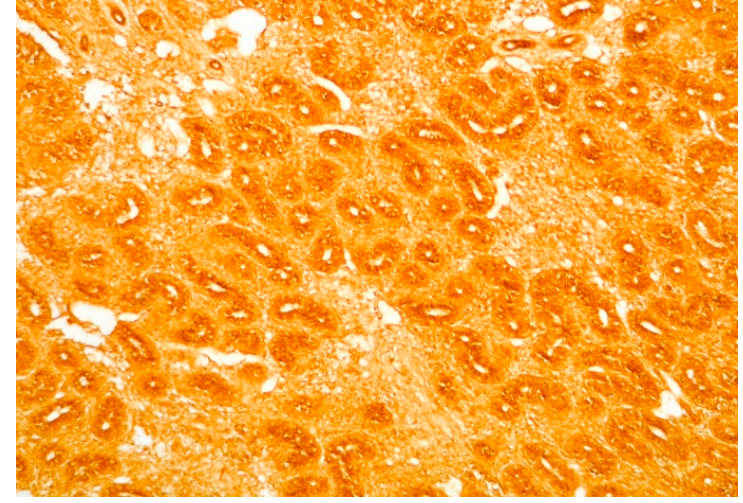

(C)

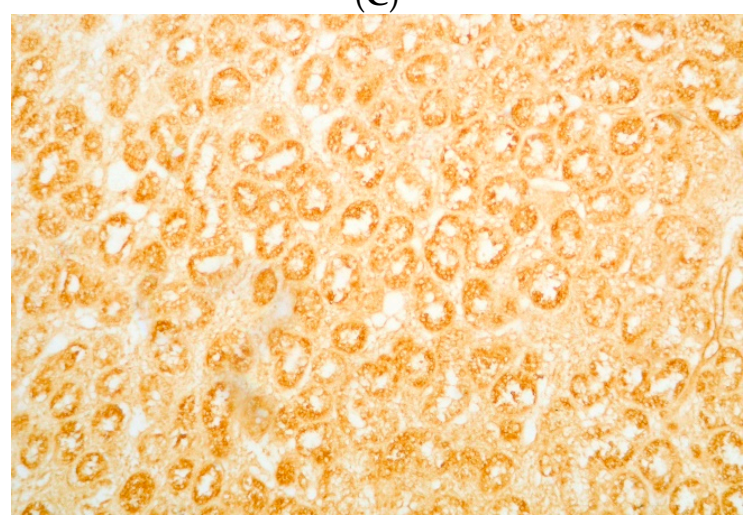

(E)

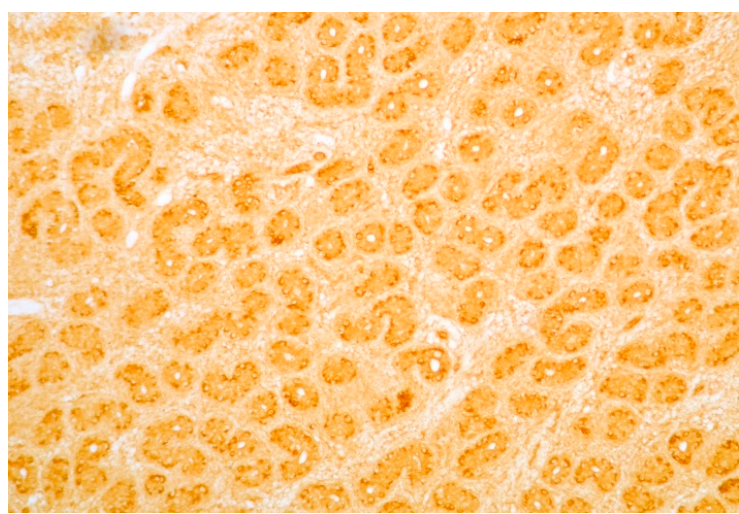

(D)

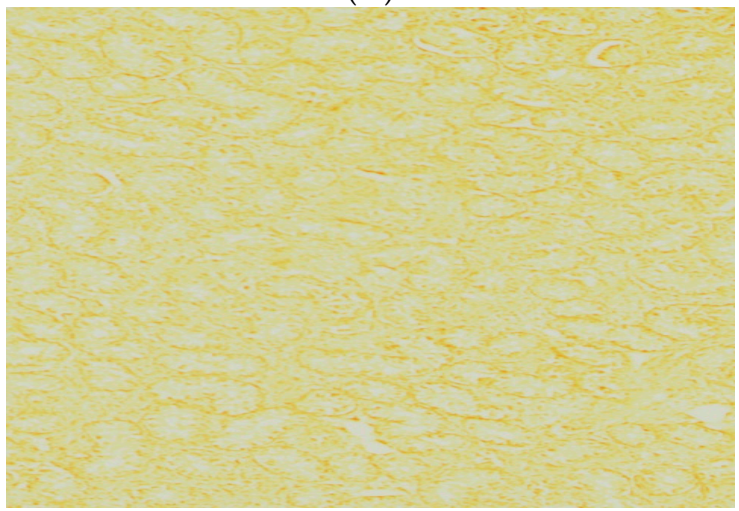

(F)

Figure 1. Immunohistochemistry detection of germ cells in testis with primary antibody against chicken Vasa $(\mathbf{A}-\mathbf{E})$ or rabbit IgG $(\mathbf{F})$. Magnification $\times 20$. Testes were obtained from chickens fed experimental diets with a final concentration of $5 \mathrm{mg}$ DON $/ \mathrm{kg} \operatorname{diet}(\mathbf{B}), 20 \mathrm{mg} \mathrm{FB} 1+\mathrm{FB} 2 / \mathrm{kg} \operatorname{diet}(\mathbf{C}), 0.5 \mathrm{mg} \mathrm{ZON} / \mathrm{kg}$ $\operatorname{diet}(\mathbf{D})$ and $5 \mathrm{mg} \mathrm{DON}+20 \mathrm{mg}$ FB1 + FB2 + $0.5 \mathrm{mg} \mathrm{ZON} / \mathrm{kg} \operatorname{diet}(\mathbf{E})$. The control diet $(\mathbf{A}, \mathbf{F})$ was free of mycotoxins.

Inflammation markers (IFN- $\gamma$ and IL1 $\beta$ ) and oxidative stress measured by TAC and catalase activity were not affected by exposure to mycotoxins. Despite the fact that testosterone and cAMP production was measured in an immature testis (before puberty, 35 days post-hatching), no effect was observed.

\subsection{Sphinganine to Sphingosine Ratio}

Free Sa and So were quantified in the liver and the Sa to So ratio was calculated (Figure 2). No significant difference in So concentration was observed among groups whereas the Sa level and the Sa to So ratio increased in broilers fed with the FB and DONFBZON diets (ANOVA, $p<0.05$ ). Complementary comparison of means (Kruskall-Wallis) revealed no significant difference in the Sa level in the liver between broilers fed the FB and DONFBZON diets, whereas the Sa/So ratio was significantly higher in chicken fed the DONFBZON diet than in chickens fed the FB diet $(p<0.05)$. This result was surprising because the total amount of FB1 + FB2 was only slightly higher in the FB diet than in the DONFBZON diet, 23.13 and $19.23 \mathrm{mg}$ FB1 + FB2/kg, respectively (Table 1). No significant difference in Sa and So contents or in the Sa/So ratio in the liver was observed between chickens fed the control diet and chickens fed the DON and ZON diets (data not shown). 

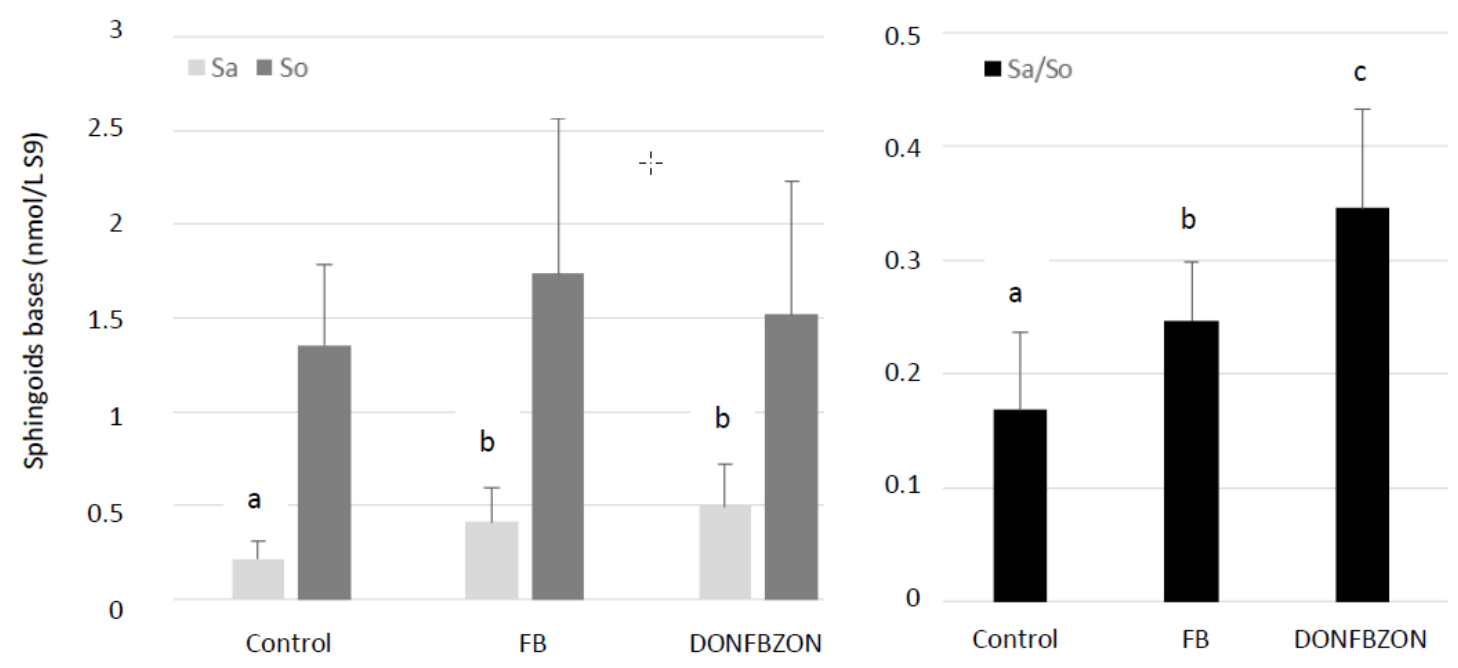

Figure 2. Effects of fumonisins on liver sphinganine (Sa). sphingosine (So) and on the sphinganine to sphingosine ratio (Sa/So) in broiler chickens fed for 35 days with a diet containing $20 \mathrm{mg}$ FB1 + FB2/kg (FB) or a diet containing deoxynivalenol, FB1 + FB2, and zearalenone (DONFBZON) at respective concentrations of 5,20 et $0.5 \mathrm{mg} / \mathrm{kg}$. The control diet (Control) was free of mycotoxins. When ANOVA revealed a significant difference $(p<0.05)$ between groups, means were compared (Kruskall-Wallis). Different letters identify statistically different groups $(p<0.05)$.

\section{Discussion}

In this study, a single exposure to DON, ZON, and FB from 0 to 35 days did not lead to any alteration in the performances of the broiler chickens or have a significant effect on organ weight, histopathology or biochemistry. These results are not surprising because single exposure involved FUS concentrations in diets that are equal to or below regulatory limits in poultry diets and these species are known to tolerate FUS [2,11,23-25]. Moreover, only a weak effect of FUS was found on intestinal morphometry of duodenum, jejunum, and on the number of goblet cells, in agreement with a long term study conducted in slow-growing chickens fed 2 to $10 \mathrm{mg}$ DON $/ \mathrm{kg}$ diet [26]. Conversely, some studies reported that DON altered the small intestinal morphology and the length of the villi in the jejunum in broilers $[27,28]$ and that FB reduced the length of the villi and the crypt depth of the ileum [29]. Differences between studies could be due to the way the toxins were added to the diet or to external factors. Indeed, studies carried out to evaluate the effects of mycotoxins can be conducted by naturally contaminated feedstuffs, culture material or pure crystalline toxins. The response from the different sources is an important contributor to the susceptibility in the model (i.e., naturally contaminated material is often more toxic in research environments presumably because other lesser-known or unknown compounds may contribute to their effects). In this study, the objective was to compare single- and multiple-dose effects of DON, ZON, and FB with the maximum recommended in poultry feed in Europe. The use of mycotoxins obtained from fungal culture extracts appeared the best way to obtain contaminated feeds with the desired exposure scenarios. Indeed, the culture material, although partially purified, still contains the metabolites that are formed in the synthesis of the final mycotoxin. Moreover, it is reasonable to assume that the mix of the extract with the feed during its manufacture results in little variation in mycotoxins bioavailability, at least compared to the administration of toxins by oral gavage [30]. With regard to external factors, this study was carried out under conditions aimed at optimizing the measurement of the effects of toxins on healthy animals. For this reason, breeding in individual cages was preferred to breeding in parquet floors. In general, farming management can change the performance and response of animals to various factors, including stress. Similarly, concomitant exposure to infectious or parasitic agents may alter the response of animals to mycotoxins, as observed in broiler chickens fed DON and FB at a not toxic level that amplified the severity of coccidiosis [19]. 
Only a few investigations have been conducted on oxidative stress in the course of FUS exposure in broiler chickens. One study reported that $7.54 \mathrm{mg}$ DON/kg feed down-regulated heme-oxygenase and upregulated xanthine oxidoreductase mRNA in the liver [31]. Another study reported that $100 \mathrm{mg}$ FB1/kg of feed increased hepatic MDA levels and CAT activity in chickens [32]. Moreover, the intake of contaminated feed containing DON and ZON in combination was reported to significantly reduce the activity of glutathione peroxidase and to increase the level of MDA in liver tissue [33]. In the present study, several variables were measured in plasma and liver to reveal oxidative stress, but none was significantly changed by FUS exposure.

Effects of FUS on reproductive function are usually not reported in avian species, except with very high levels of ZON [11,34]. The weights of testes were significantly reduced in broilers fed 200 to $400 \mathrm{mg}$ $\mathrm{ZON} / \mathrm{kg}$ [35]. In mammals, the most toxic effect of FUS other than $\mathrm{ZON}$ on reproductive function has been mild-to-moderate lesions of testes with Sertoli cell degeneration and impaired spermatogenesis observed in rabbits fed 0.13 to $5 \mathrm{mg}$ FB1/ $\mathrm{kg}$ diet for 175 days [36,37]. Studies conducted in mice suggested that DON may have an adverse effect on the epididymal weight at $10 \mathrm{mg} / \mathrm{kg}$ of feed for 90 days with slight changes in relative testis weight and spermatid counts, but no histological changes [38]. In the present study, no significant difference was observed in the variables measured to reveal toxicity of FUS in broiler testes except a decrease in the diameter of the seminiferous tubule and a decrease in catalase activity in the DONFBZON group that are difficult to interpret. All these results confirm that broilers are less sensitive to the toxic reproductive effects of FUS than mammals, even when a mixture of toxins was used.

Using biomarkers of effects is a good way to reveal the effect of mycotoxins on health at a level of exposure lower than one that is toxic. Alteration of sphingolipid metabolism has been known for several years to be the best biomarker of FB exposure in most animal species, including poultry $[9,11]$. In the present study, a significant increase in the level of Sa in liver concomitant with an increase in the Sa/So ratio was observed in the FB-treated group compared to the control group. This result is in agreement with previous data obtained with higher levels of FB in broiler chicken diets, and with data obtained in plasma using the same dose $[29,38]$. Together, the lack of histopathological damage to the liver and the lack of increase in LDH activity in plasma confirmed the alteration of sphingolipid metabolism occurred at a level of FB that is not hepatotoxic in broiler chickens.

Taken together, these results confirm that single exposure of broiler chickens from 1 to 35 days of age to FUS concentrations in diets that are equal to or below regulatory limits for poultry feed had no deleterious effect on health. Interestingly, no additive, synergistic or antagonist effect on the variables measured was observed in broilers exposed to the diet containing a mixture of DON, FB, and ZON at similar levels as those used in formulation trials conducted with a single toxin. Although previous studies on chickens revealed interactions between FUS, no study was conducted using EU regulatory limits. Concerning sphingolipids in the liver, the Sa/So ratio was significantly higher in chickens fed the DONFBZON diet than in chickens fed the diet containing FB alone, whereas the measured concentration of FB1 + FB2 was higher in the FB diet than in the DONFBZON diet. The apparent synergistic effect of FUS on the Sa/So ratio should be interpreted with caution and should take the effects on Sa and So and not only the effects on the Sa/So ratio into account. Indeed, previous studies on ducks and turkeys with low doses of FB demonstrated that the level of FB1 in the diet is always correlated with an increase in Sa content in the liver. By contrast, the effects of low doses of FB1 on So content are less pronounced and vary with the study [39-41]. Moreover, most studies on avian species have shown that toxic levels of FB in diets are responsible for the liberation of LDH by the hepatocytes in plasma and for an increase in LDH activity in this medium [41-44], which was not the case in our chickens fed the DONFBZON diet.

In conclusion, this study demonstrated for the first time the lack of strong interactions between DON, FB and ZON fed alone or in combination to broiler chickens from 1 to 35 days in age on the variables measured. Together, the lack of effect of these toxins on performances, organ weight, biochemistry, histopathology, variables of oxidative damage and markers of testis toxicity suggest that 
the regulatory guidelines established for single contamination of broiler chickens fed DON, FB and $\mathrm{ZON}$ can be used in the case of multiple contamination with these toxins.

\section{Materials and Methods}

\subsection{Fusariotoxin Production and Experimental Diets}

All the experimental diets containing mycotoxins incorporated ground cultured toxigenic Fusarium strains. Briefly, fumonisins were produced on crushed corn at $25{ }^{\circ} \mathrm{C}$ using F. verticillioides strain L12. Deoxynivalenol was produced by growing F. graminearum strain $\mathrm{I} 159$ on wheat at $23^{\circ} \mathrm{C}$, and zearalenone was obtained by culturing $F$. graminearum strain II71 on rice at $21^{\circ} \mathrm{C}$. After four weeks of growth, the cultured Fusarium species were dried at $90{ }^{\circ} \mathrm{C}$ for $3 \mathrm{~h}$, ground and sieved through a $0.6 \mathrm{~mm}$ mesh. The concentrations of mycotoxins in the powders were measured by HPLC-MSMS.

Experimental corn-soybean diets were used to best meet the nutritional needs of the animals. One feed was formulated for 0 to 10 days of age $(\mathrm{CP}=22 \%, \mathrm{ME}=2880 \mathrm{kcal} / \mathrm{kg})$ and another for 11 to 35 days of age $(\mathrm{CP}=19.5 \%$ and $\mathrm{ME}=3050 \mathrm{kcal} / \mathrm{kg})$. Powders containing the mycotoxins were incorporated to obtain 10 different experimental diets (Table 1). The control diets (Control) were free of mycotoxins. The deoxynivalenol (DON), fumonisin ( $\mathrm{FB})$, and zearalenone ( $\mathrm{ZON}$ ) diets were made by incorporating powdered cultured materials to obtain $5 \mathrm{mg}$ DON $/ \mathrm{kg}, 20 \mathrm{mg}$ FB1 + FB2/ $/ \mathrm{kg}$, and $0.5 \mathrm{mg} \mathrm{ZON} / \mathrm{kg}$, respectively. The three toxins were added in the diet that contained the mixture of fusariotoxins (DONFBZON) at concentrations of 5, 20 and $0.5 \mathrm{mg} / \mathrm{kg}$ for DON, FB1 + FB2, and ZON, respectively. The concentrations of mycotoxins in the different diets was checked by HPLC-MSMS.

\subsection{Mycotoxin Analysis}

The concentrations of mycotoxins in the culture material and in the experimental diets were analysed by HPLC-MSMS according to the AFNOR V03-110 recommendation [45]. All reactants were of HPLC analytical grade except pure water and acetic acid that were of HPLC-MS grade (Fluka, Buchs, Switzerland). Stock solutions of standard mycotoxins (Romer Labs, 3131 Getzersdorf, Austria) prepared in acetonitrile were solubilized with $0.01 \%$ of acetic acid for HPLC-MS/MS calibration. Mycotoxins assayed were diacetoxyscirpenol, 15 monocetoxyscirpenol, T2 toxin, HT2 toxin, T2 tetraol, verrucarol, desoxynivalenol, desoxynivalenol-3-glucoside, deepoxy-deoxynivalenol, 15-acetyl-deoxynivalenol, 3-acetyl-deoxynivalenol, fusarenone $x$, nivalenol, roridin A, verrucarin A, fumonisin B1, fumonisin B2, fumonisin B3, moniliformine, zearalenone, alpha-zearalenol, beta-zearalenol, zearalenone, alpha-zearalanol, beta-zearalanol, tenuazonic acid, ergocornine, ergocristine, ergocryptine, ergometrine, ergosine, ergotamine, aflatoxin B1, aflatoxin B2, aflatoxin G1, aflatoxin G2, ochratoxin A, ochratoxin B, alpha-ochratoxin, cyclopiazonic acid, citrinin, patulin, and sterigmatocystin. The HPLC was performed using Hewlett Packard type 1100 (Hewlett Packard, Eybens 38, France) in the following conditions: Column $250 \mathrm{~mm} \times 4.6$ packed with $\mathrm{C}_{18}$ phase (VWR Pessac 33, France Applied Biosystems, Foster City, CA, USA). Mobile phase: Ammonium acetate $1 \mathrm{nM}$ and $0.0001 \%$ acetic acid/methanol and $1 \%$ acetonitrile. A linear gradient was applied for $40 \mathrm{~min}$ at a flow rate of $1 \mathrm{~mL} / \mathrm{min}$. Detection was performed with a quadrupole tandem mass spectrometer API 4000 (Applied Biosystems, Foster City, CA, USA) at a source temperature of $500{ }^{\circ} \mathrm{C}$ with a $4500 \mathrm{~V}$ ion spray voltage in positive and negative mode interface. Each mycotoxin was identified and quantified on two or three transitions. Experimental diets $(1 \mathrm{~kg})$ were ground to a fine powder and sifted through a $0.5 \mathrm{~mm}$ particle size filter. Five $\mathrm{g}$ of sieved samples were extracted for $2 \mathrm{~h}$ by reversal agitation with $20 \mathrm{~mL}$ of acetonitrile/water. The extract was centrifuged, and $3 \mathrm{~mL}$ of the aqueous phase were evaporated to dryness. The dry residue was dissolved in a solution of $0.01 \%$ acetic acid methanol $(2 / 1, v / v)$, filtered on a syringe, and injected in the HPLC-MS/MS. The limit of quantitation ranged from 1 to $10 \mu \mathrm{g} / \mathrm{kg}$, depending on the mycotoxin. 


\subsection{Animal Husbandry and Sample Collection}

All experimental procedures with animals were in accordance with the French National Guidelines for the care and use of animals for research purposes. The experimental protocol was approved by the French Ministry of Higher Education and Research and registered under number 02032.01. Seventy broilers (male Ross PM3) were reared in individual cages in an experimental station (ARVALIS-Institut du vegetal, Villerable, France). Each experimental diet was distributed to 14 broilers ad libitum throughout the experiment along with ad libitum access to water. Individual body weight and feed consumption were measured weekly. On the 35th day of age, after a starvation period of $8 \mathrm{~h}$, a blood sample was collected. Samples were centrifuged and serum was collected and stored at $-80^{\circ} \mathrm{C}$ until analysis. The animals were stunned by electrocution and killed by exsanguination. Autopsies were performed on all the animals to investigate macroscopic lesions and to examine the color of the liver and cecum tonsils. The heart, liver, spleen, thymus, pancreas, kidneys, and testicles were collected and weighed. The intestine was emptied, then the gizzard, proventriculus, duodenum, jejunum, ileum, and caeca (including caeca tonsils) were isolated and weighed. The length of the duodenum, jejunum and ileum segments was measured. The color of the liver and cecum tonsils was measured with a chromameter (Konica Minolta, Europe). Samples of liver, kidney, spleen, duodenum, jejunum, ileum, caecum, caeca tonsils, and Fabricius bursa were placed in 10\% formaldehyde for microscopic examination. The remaining liver and testicles were stored at $-80^{\circ} \mathrm{C}$ until analysis.

\subsection{Biochemistry, Hematology, and Histopathology}

Plasma concentrations of lactate dehydrogenase (LDH) EC 1.1.1.27, alkaline phosphatase (ALP) EC 3.1.3.1, and alanine aminotransferase (ALT) EC 2.6.1.2 were analyzed using a clinical chemistry KONELAB 20 analyzer (Fisher Scientific SAS, Illkirch, France) and are expressed in UI/L according to international guidelines. Proteins, cholesterol, and uric acid were measured according to the manufacturer's instructions and are expressed in $\mathrm{g} / \mathrm{L}$ or mmol/L of plasma. Immunoglobulin A (IgA) assays were performed using the chicken IgA Elisa kit following the manufacturer's instructions (Bethyl Laboratories Inc., Montgomery, TX, USA). Hemoglobin ( $\mathrm{Hb})$ and erythrocytes contents were measured using Hycel Celly analyzer (EUROCELL Diagnostics, Rennes, France) and are expressed in $\mathrm{mg} / \mathrm{L}$ and in $10^{3}$ number of cells/mL, respectively. The white blood cell count was done manually in Malassez cells, and the results are expressed in $10^{3}$ number of cells $/ \mathrm{mL}$.

Except for the testes, fixed tissues were trimmed, embedded in paraffin, and $4 \mu \mathrm{m}$ sections cut with a microtome, and stained with hematoxylin, eosin, and saffron (HES). All the tissues from the control and treated groups were examined microscopically. Fixed testes were processed in paraffin and serially sectioned at $7 \mu \mathrm{m}$. The diameter of the seminiferous tubules was measured with round or nearly round tubules from each testicular section stained with Meyer's hematoxylin (Sigma, l'Isle d'Abeau Chesnes, France). At least 40 measurements of the diameter of the transverse sections of seminiferous tubules were measured using an ocular measuring device. Four different chickens were analyzed per treatment.

\subsection{Immunohistochemistry and Detection of Apoptosis}

Testes embedded in paraffin were serially sectioned at $7 \mu \mathrm{m}$. Deparaffinized sections were hydrated, microwaved for $5 \mathrm{~min}$ in an antigen unmasking solution (Vector Laboratories, Inc., AbCys, Paris, France), and left to cool to room temperature. The sections were washed in a PBS bath for 5 min and immersed in peroxidase blocking reagent at room temperature for $10 \mathrm{~min}$ to quench endogenous peroxidase activity (DAKO Cytomation, Dako, Ely, UK). After two PBS baths for 5 min, nonspecific background was prevented by incubation in $5 \%$ lamb serum/PBS for $30 \mathrm{~min}$. Finally, the sections were incubated with PBS containing primary antibody against chicken Vasa overnight at $4{ }^{\circ} \mathrm{C}$ [46]. The following day, after two PBS baths for $5 \mathrm{~min}$, sections were incubated for $30 \mathrm{~min}$ at room temperature with "ready to use" labeled Polymer-HRP anti-rabbit (DAKO Cytomation, Dako, Ely, UK). Finally, 
after two baths in PBS, staining was revealed by incubation with a 3,3'-diaminobenzidine tablet (Sigma, l'Isle d'Abeau Chesnes, France) dissolved in deionized water at room temperature. Negative controls were incubated with rabbit IgG.

Apoptosis was detected on deparaffinized sections hydrated and permeabilized with Proteinase $\mathrm{K}$ as described in the instruction manual (FragEL kit, Calbiochem, VWR, West Chester, PA, USA). Endogenous peroxidases were inactivated by incubation in $3 \% \mathrm{H}_{2} \mathrm{O}_{2}$, then the nuclear DNA fragments were end-labeled in situ in a humid chamber for $1.5 \mathrm{~h}$ at $37^{\circ} \mathrm{C}$ by terminal deoxynucleotidyl transferase (TdT). Staining was revealed with 3,3'-diaminobenzidine (DAB), negative controls were TdT-free [47].

\subsection{Liver Fractions and Protein Concentration}

Four grams of liver were homogenized in $12 \mathrm{~mL}$ pH 7.4 phosphate buffer $(0.1 \mathrm{M}, 0.1 \mathrm{M}$ Tris acetate, $0.1 \mathrm{M} \mathrm{KCl}, 1 \mathrm{mM}$ EDTA and $0.02 \mathrm{M}$ butylated hydroxytoluene) at $4{ }^{\circ} \mathrm{C}$. The homogenate was centrifuged at $9000 \times g$, for $30 \mathrm{~min}$ at $4{ }^{\circ} \mathrm{C}$, and the supernatant (S9) was collected. Five hundred microliters of the S9 fraction were deproteinized with metaphosphoric acid $(1.25 \mathrm{M}, \mathrm{vol} / \mathrm{vol})$ and stored at $-80{ }^{\circ} \mathrm{C}$ until further analysis to determine glutathione content. The remainder of the S9 fraction was stored at $-80^{\circ} \mathrm{C}$ for further analysis. The protein concentration in the $\mathrm{S} 9$ fraction was measured using the Bio-Rad kit protein assay (Bio-Rad Laboratories, München, Germany).

\subsection{Oxidative Markers and Antioxidant Enzyme Activity in Plasma and Liver}

Malondialdehyde (MDA) was measured fluorometrically (excitation: $515 \mathrm{~nm}$, emission: $548 \mathrm{~nm}$ ) in plasma and in the $\mathrm{S} 9$ fraction of liver $(1 \mathrm{mg}$ protein $/ \mathrm{mL}$ ) after butanol extraction of a pink complex formed with thiobarbituric acid [48-50]. Total glutathione (TGlu) was measured with Ellman's reagent using an optimized enzymatic recycling method for the quantification of reduced glutathione (GSH). Briefly, GSH reacts with 5,5'-dithio-bis-(2-nitrobenzoic acid) to produce 5-thio-2-nitrobenzoic acid (TNB) and Gs-TNB. Both oxidized glutathione (GSSG) and Gs-TNB are reduced by glutathione reductase to recycle the GSH, which produces more TNB. The rate of TNB was measured spectrophotometrically at $405 \mathrm{~nm}$. Dilution (1/100) of the deproteinized S9 fraction was required before it was measured in the S9 samples. Oxidized glutathione, exclusive of GSH, was obtained by the first derivatization of GSH with 1 M 2-vinylpyridine before measurement of total glutathione (Baker et al., 1990; Griffith, 1980).

Superoxide dismutase (SOD, EC 1.15.1.1) activity was measured in plasma (5 mg protein $/ \mathrm{mL}$ ) and in the S9 fraction of liver (50 $\mathrm{g}$ protein $/ \mathrm{mL}$ ). Measurement was based on the inhibition of the formation of blue formazan by xanthine-xanthine oxidase (EC 1.17.3.2) in the presence of nitroblue tetrazolium (Sun et al., 1988). The reaction was monitored spectrophotometrically at $540 \mathrm{~nm}$, and SOD activity was calculated by linear regression using bovine erythrocyte SOD as standard. Catalase (CAT, EC 1.11.1.6) activity was estimated by the formation of formaldehyde from methanol in the presence of $\mathrm{H}_{2} \mathrm{O}_{2}$. Formaldehyde reacts with Purpald reagent to form a complex that is dosed at 540 nm (Johansson and Håkan Borg, 1988). Glutathione reductase (GR, EC 1.6.4.2) reduces GSSG into GSH in the presence of nicotinamide adenosine phosphate (NADPH) (Carlberg and Mannervik, 1984). Glutathione peroxidase (GPx, EC 1.11.1.9) reduces cumene hydroperoxide in the presence of GSH to produce GSSG, which is recycled into GSH by GR in the presence of NADPH (Paglia and Valentine, 1967). GR and GPx activities were measured separately in plasma (5 $\mathrm{mg}$ protein/mL, $12 \mathrm{~min}$ of kinetics) and in the S9 fraction (1 $\mathrm{mg}$ protein/mL, $2 \mathrm{~min}$ of kinetics) by monitoring the decrease in NADPH content at $340 \mathrm{~nm}$.

\subsection{Testis Extracts and Assays}

Testis extracts were obtained after three repeated freeze/thaw cycles in PBS. The protein concentration in the supernatant was determined using a colorimetric assay kit (Uptima Interchim, Montluçon, France).

Caspase 3/7 Glow assays were performed according to the manufacturer's instructions (Promega, Charbonnieres les Bains, France). The quantification of caspase-3/7 activity uses a luminogenic 
substrate containing the sequence asp-glu-val-asp, and after cleavage by caspases, a luciferin substrate is liberated and is used by luciferase to generate light. The amount of luminescence is proportional to the amount of caspase activity present in the cell lysate. Luminescence was measured in relative light units and normalized to 100,000 seminiferous tubule cells.

The chicken proliferating cell nuclear antigen (PCNA) was measured to analyze cell proliferation, whereas when azoospermia-like protein (DAZL) is deleted, this is a marker of spermatogonia used to reveal the immature germ cell content. Interleukin $1 \beta(\mathrm{Il} \beta)$, and interferon- $\gamma(\mathrm{IFN}-\gamma)$ concentrations were quantified to assess inflammatory response in the testis. All standards and samples were assayed according to the manufacturer's recommendations (Cusabio, Eurobio, Courtaboeuf, France).

Total antioxidant capacity (TAC) and catalase activity were measured by the Cayman's antioxidant assay kit according to the instruction manual (Cayman, Interchim, Montluçon, France). Assay plates were red by using an ELISA plate reader at $750 \mathrm{~nm}$ for TAC and at $540 \mathrm{~nm}$ for catalase activity. The TAC assay is based on the ability of antioxidants (vitamins, proteins, lipids, glutathione, uric acid, etc.) to inhibit the oxidation of 2,2'-azino-bis,3-ethylbenzthiazoline-6-sulphonic acid. Total antioxidant capacity is expressed as Trolox equivalent antioxidant capacity per mg of testicular protein extract.

The concentration of cAMP was measured using the cAMP-Glo assay as recommended by the manufacturer (Promega, Madison, WI, USA). The concentration of testosterone was assessed by radioimmunoassay in duplicate as previously described [51]. The sensitivity test was $15 \mathrm{pg} /$ tube and intra-assay coefficients of variation of $5.3 \%$.

\subsection{Determination of the Sphinganine to Sphingosine Ratio}

Calculation of the sphinganine (Sa) to sphingosine (So) ratio requires prior determination of free Sa and free So contents (Riley et al., 1994a). Briefly, $0.2 \mathrm{nmol}$ of $\mathrm{C}_{20}$ sphinganine (Matreya, Inc., Pleasant Gap, PA, USA) used as internal standard were added to $100 \mu \mathrm{L}$ of plasma or S9. Sphingolipids were extracted by alkaline methanolic-chloroform and the chloroform phase was washed twice with alkaline water. Extracts were dried under nitrogen flow, then suspended in $20 \mu \mathrm{L}$ methanol, and sonicated for $10 \mathrm{~min}$. Derivatization of sphingolipid was performed with ortho-phthalaldehyde before injection using automate (ICS M2200, Toulouse, France). The HPLC system is composed of an ICS M2200 HPLC autosampler (ICS, Toulouse, France) that delivers methanol-water $(90: 10, v / v)$ to a Prontosil C18 cartridge equipped with a C18 pre-column filter (Bischoff, Leonberg, Germany). A fluorescence detector (FD-500 Shimazu, Kyoto, Japan) was used for detection, the excitation wavelength was $335 \mathrm{~nm}$, and the emission wavelength $440 \mathrm{~nm}$. Mean retention times were 12, 17 and $29 \mathrm{~min}$ for sphingosine, sphinganine and $\mathrm{C}_{20}$ sphinganine, respectively. Concentrations were calculated by linear regression from standard solutions that were injected daily. $\mathrm{C}_{20}$ sphinganine was used as an internal standard to monitor the extraction rate the sphingolipids in the samples.

\subsection{Statistical Analysis}

Data on all response variables are reported as means \pm SD or SEM and were the subject of one-way analysis of variance (ANOVA) after a normality test (Shapiro-Wilk). When a significant difference was observed $(p<0.05)$, the difference between means was determined by individual comparison of means (Kruskall-Wallis). Statistically different groups $(p<0.05)$ are identified by a different letter. All statistical analyses were conducted by XLSTAT Biomed.

Author Contributions: Conceptualization: J.-P.M., A.T., A.M., J.-D.B., D.C., C.B., J.L.G., P.F., O.A., S.L., G.L., E.M., D.T., P.G.; investigation: J.-P.M., A.T., A.M., J.-D.B., D.C., C.B., J.L.G., P.F., O.A., S.L., G.L., E.M., D.T., P.G.; validation: J.-P.M., A.T., A.M., J.-D.B., D.C., C.B., J.L.G., P.F., O.A., S.L., G.L., E.M., D.T., P.G.

Funding: This study was supported by CASDAR grants (project 2012-2015 MYCOVOL). The authors would like to thank the RMT Quasaprove for supporting the project.

Conflicts of Interest: The authors declare no conflict of interest. 


\section{Abbreviations}

\begin{tabular}{ll} 
FUS & fusariotoxins \\
$\mathrm{FB}_{1}$ & fumonisin B1 \\
$\mathrm{FB}_{2}$ & fumonisin $\mathrm{B} 2$ \\
$\mathrm{FB}_{3}$ & fumonisin B3 \\
$\mathrm{DON}$ & deoxynivalenol \\
ZON & zearalenone \\
BW & body weight \\
DWG & daily weight gain \\
FCR & feed conversion ratio \\
RW & relative weights \\
LDH & lactate dehydrogenase \\
ALP & alkaline phosphatase \\
ALT & alanine aminotransferase \\
IgA & Immunoglobulin A \\
Hb & hemoglobin \\
MDA & malondialdehyde \\
TGlu & total glutathione \\
GSSG & oxidized glutathione \\
GSH & reduced glutathione \\
SOD & superoxide dismutase \\
CAT & catalase \\
CH ${ }_{2} \mathrm{O}$ & formaldehyde \\
GPx & glutathione peroxidase \\
GRed & glutathione reductase \\
NADPH & nicotinamide adenine dinucleotide phosphate \\
HES & hematoxylin; eosin and saffron \\
TdT & deoxynucleotidyl transferase \\
DAB & $3,3^{\prime}$-diaminobenzidine \\
TAC & Total antioxidant capacity \\
Il $\beta$ & Interleukin $1 \beta$ \\
IFN- $\gamma$ & Interferon- $\gamma$ \\
PCNA & proliferating cell nuclear antigen \\
DAZL & deleted in azoospermia-like \\
Sa & sphinganine \\
So & \\
& sphingosine \\
\hline
\end{tabular}

\section{References}

1. Binder, E.M.; Tan, L.M.; Chin, L.J.; Handl, J.; Richard, J. Worldwide occurrence of mycotoxins in commodities, feeds and feed ingredients. Anim. Feed Sci. Technol. 2007, 137, 265-282. [CrossRef]

2. Guerre, P. Worldwide Mycotoxins Exposure in Pig and Poultry Feed Formulations. Toxins 2016, 8, 350. [CrossRef] [PubMed]

3. Kosicki, R.; Błajet-Kosicka, A.; Grajewski, J.; Twarużek, M. Multiannual mycotoxin survey in feed materials and feedingstuffs. Anim. Feed Sci. Technol. 2016, 215, 165-180. [CrossRef]

4. Krska, R.; Welzig, E.; Boudra, H. Analysis of Fusarium toxins in feed. Anim. Feed Sci. Technol. 2007, 137, 241-264. [CrossRef]

5. Pinotti, L.; Ottoboni, M.; Giromini, C.; Dell'Orto, V.; Cheli, F. Mycotoxin contamination in the EU feed supply chain: a focus on cereal byproducts. Toxins 2016, 8, 45. [CrossRef] [PubMed]

6. Zachariasova, M.; Dzuman, Z.; Veprikova, Z.; Hajkova, K.; Jiru, M.; Vaclavikova, M.; Zachariasova, A.; Pospichalova, M.; Florian, M.; Hajslova, J. Occurrence of multiple mycotoxins in European feedingstuffs, assessment of dietary intake by farm animals. Anim. Feed Sci. Technol. 2014, 193, 124-140. [CrossRef]

7. Bryden, W.L. Mycotoxin contamination of the feed supply chain: Implications for animal productivity and feed security. Anim. Feed Sci. Technol. 2012, 173, 134-158. [CrossRef] 
8. Grenier, B.; Oswald, I. Mycotoxin co-contamination of food and feed: meta-analysis of publications describing toxicological interactions. World Mycotoxin J. 2011, 4, 285-313. [CrossRef]

9. Magnin, M.; Travel, A.; Bailly, J.D.; Guerre, P. Effets des mycotoxines sur la santé et les performances des volailles. INRA Prod. Anim. 2016, 29, 217-232.

10. Morgavi, D.P.; Riley, R.T. An historical overview of field disease outbreaks known or suspected to be caused by consumption of feeds contaminated with Fusarium toxins. Anim. Feed Sci. Technol. 2007, 137, 201-212. [CrossRef]

11. Murugesan, G.R.; Ledoux, D.R.; Naehrer, K.; Berthiller, F.; Applegate, T.J.; Grenier, B.; Phillips, T.D.; Schatzmayr, G. Prevalence and effects of mycotoxins on poultry health and performance, and recent development in mycotoxin counteracting strategies. Poult. Sci. 2015, 94, 1298-1315. [CrossRef] [PubMed]

12. Lee, J.T.; Jessen, K.A.; Beltran, R.; Starkl, V.; Schatzmayr, G.; Borutova, R.; Caldwell, D.J. Mycotoxin-contaminated diets and deactivating compound in laying hens: 1 . effects on performance characteristics and relative organ weight. Poult. Sci. 2012, 91, 2089-2095. [CrossRef] [PubMed]

13. Lee, J.T.; Jessen, K.A.; Beltran, R.; Starkl, V.; Schatzmayr, G.; Borutova, R.; Caldwell, D.J. Effects of mycotoxin-contaminated diets and deactivating compound in laying hens: 2. effects on white shell egg quality and characteristics. Poult. Sci. 2012, 91, 2096-2104. [CrossRef] [PubMed]

14. Li, Z.; Yang, Z.B.; Yang, W.R.; Wang, S.J.; Jiang, S.Z.; Wu, Y.B. Effects of feed-borne Fusarium mycotoxins with or without yeast cell wall adsorbent on organ weight, serum biochemistry, and immunological parameters of broiler chickens. Poult. Sci. 2012, 91, 2487-2495. [CrossRef] [PubMed]

15. Siloto, E.V.; Oliveira, E.F.A.; Sartori, J.R.; Fascina, V.B.; Martins, B.A.B.; Ledoux, D.R.; Rottinghaus, G.E.; Sartori, D.R.S. Lipid metabolism of commercial layers fed diets containing aflatoxin, fumonisin, and a binder. Poult. Sci. 2013, 92, 2077-2083. [CrossRef] [PubMed]

16. Wan, X.L.; Yang, Z.B.; Yang, W.R.; Jiang, S.Z.; Zhang, G.G.; Johnston, S.L.; Chi, F. Toxicity of increasing aflatoxin B1 concentrations from contaminated corn with or without clay adsorbent supplementation in ducklings. Poult. Sci. 2013, 92, 1244-1253. [CrossRef] [PubMed]

17. Yang, Z.B.; Wan, X.L.; Yang, W.R.; Jiang, S.Z.; Zhang, G.G.; Johnston, S.L.; Chi, F. Effects of naturally mycotoxin-contaminated corn on nutrient and energy utilization of ducks fed diets with or without Calibrin-A. Poult. Sci. 2014, 93, 2199-2209. [CrossRef]

18. Kubena, L.F.; Edrington, T.S.; Harvey, R.B.; Buckley, S.A.; Phillips, T.D.; Rottinghaus, G.E.; Casper, H.H. Individual and combined effects of fumonisin B1 present in Fusarium moniliforme culture material and T-2 toxin or deoxynivalenol in broiler chicks. Poult. Sci. 1997, 76, 1239-1247. [CrossRef]

19. Grenier, B.; Dohnal, I.; Shanmugasundaram, R.; Eicher, S.D.; Selvaraj, R.K.; Schatzmayr, G.; Applegate, T.J. Susceptibility of Broiler Chickens to Coccidiosis When Fed Subclinical Doses of Deoxynivalenol and Fumonisins-Special Emphasis on the Immunological Response and the Mycotoxin Interaction. Toxins 2016, 8 , 231. [CrossRef]

20. Zou, Y.; Yang, Z.B.; Yang, W.R.; Jiang, S.Z.; Zhang, G.G.; Chi, F. Effect of purified zearalenone on nutrient digestibility in broilers fed 2 levels of Fumonisin from naturally contaminated corn (Zea mays). J. Appl. Poult. Res. 2012, 21, 251-258. [CrossRef]

21. Speijers, G.J.A.; Speijers, M.H.M. Combined toxic effects of mycotoxins. Toxicol. Lett. 2004, 153, 91-98. [CrossRef] [PubMed]

22. Commission Recommendation of 17 August 2006 on the Presence of Deoxynivalenol, Zearalenone, Ochratoxin A, T-2 and HT-2 and Fumonisins in Products Intended for Animal Feeding. Available online: http://eur-lex. europa.eu/legal-content/EN/TXT/PDF/?uri=CELEX:32006H0576\&from=EN (accessed on 11 August 2016).

23. Fink-Gremmels, J.; Malekinejad, H. Clinical effects and biochemical mechanisms associated with exposure to the mycoestrogen zearalenone. Anim. Feed Sci. Technol. 2007, 137, 326-341. [CrossRef]

24. Pestka, J.J. Deoxynivalenol: Toxicity, mechanisms and animal health risks. Anim. Feed Sci. Technol. 2007, 137, 283-298. [CrossRef]

25. Voss, K.A.; Smith, G.W.; Haschek, W.M. Fumonisins: Toxicokinetics, mechanism of action and toxicity. Anim. Feed Sci. Technol. 2007, 137, 299-325. [CrossRef]

26. Chen, S.S.; Li, Y.-H.; Lin, M.-F. Chronic Exposure to the Fusarium Mycotoxin Deoxynivalenol: Impact on Performance, Immune Organ, and Intestinal Integrity of Slow-Growing Chickens. Toxins 2017, 9, 334. [CrossRef] [PubMed] 
27. Awad, W.A.; Hess, M.; Twarużek, M.; Grajewski, J.; Kosicki, R.; Böhm, J.; Zentek, J. The impact of the Fusarium mycotoxin deoxynivalenol on the health and performance of broiler chickens. Int. J. Mol. Sci. 2011, 12, 7996-8012. [CrossRef] [PubMed]

28. Yunus, A.W.; Blajet-Kosicka, A.; Kosicki, R.; Khan, M.Z.; Rehman, H.; Böhm, J. Deoxynivalenol as a contaminant of broiler feed: intestinal development, absorptive functionality, and metabolism of the mycotoxin. Poult. Sci. 2012, 91, 852-861. [CrossRef]

29. Antonissen, G.; Croubels, S.; Pasmans, F.; Ducatelle, R.; Eeckhaut, V.; Devreese, M.; Verlinden, M.; Haesebrouck, F.; Eeckhout, M.; De Saeger, S.; et al. Fumonisins affect the intestinal microbial homeostasis in broiler chickens, predisposing to necrotic enteritis. Vet. Res. 2015, 46, 98. [CrossRef]

30. Guerre, P. Fusariotoxins in Avian Species: Toxicokinetics, Metabolism and Persistence in Tissues. Toxins 2015, 7, 2289-2305. [CrossRef]

31. Osselaere, A.; Santos, R.; Hautekiet, V.; De Backer, P.; Chiers, K.; Ducatelle, R.; Croubels, S. Deoxynivalenol Impairs Hepatic and Intestinal Gene Expression of Selected Oxidative Stress, Tight Junction and Inflammation Proteins in Broiler Chickens, but Addition of an Adsorbing Agent Shifts the Effects to the Distal Parts of the Small Intestine. PLoS ONE 2013, 8, e69014. [CrossRef]

32. Poersch, A.B.; Trombetta, F.; Braga, A.C.M.; Boeira, S.P.; Oliveira, M.S.; Dilkin, P.; Mallmann, C.A.; Fighera, M.R.; Royes, L.F.F.; Oliveira, M.S.; et al. Involvement of oxidative stress in subacute toxicity induced by fumonisin B1 in broiler chicks. Vet. Microbiol. 2014, 174, 180-185. [CrossRef] [PubMed]

33. Borutova, R.; Faix, S.; Placha, I.; Gresakova, L.; Cobanova, K.; Leng, L. Effects of deoxynivalenol and zearalenone on oxidative stress and blood phagocytic activity in broilers. Arch. Anim. Nutr. 2008, 62, 303-312. [CrossRef] [PubMed]

34. Cortinovis, C.; Pizzo, F.; Spicer, L.J.; Caloni, F. Fusarium mycotoxins: Effects on reproductive function in domestic animals-A review. Theriogenology 2013, 80, 557-564. [CrossRef] [PubMed]

35. Allen, N.K.; Mirocha, C.J.; Weaver, G.; Aakhus-Allen, S.; Bates, F. Effects of dietary zearalenone on finishing broiler chickens and young turkey poults. Poult. Sci. 1981, 60, 124-131. [CrossRef] [PubMed]

36. Ewuola, E.O.; Egbunike, G.N. Effects of dietary fumonisin B1 on the onset of puberty, semen quality, fertility rates and testicular morphology in male rabbits. Reproduction 2010, 139, 439-445. [CrossRef] [PubMed]

37. Ewuola, E.O.; Egbunike, G.N. Gonadal and extra-gonadal sperm reserves and sperm production of pubertal rabbits fed dietary fumonisin B1. Anim. Reprod. Sci. 2010, 119, 282-286. [CrossRef] [PubMed]

38. European Food Safety Authority (EFSA). Opinion of the Scientific Panel on Contaminants in Food Chain on a Request from the Commission Related to Fumonisins as Undesirable Substances in Animal Feed; EFSA: Parma, Italy, 2015. [CrossRef]

39. Tardieu, D.; Bailly, J.-D.; Skiba, F.; Métayer, J.-P.; Grosjean, F.; Guerre, P. Chronic toxicity of fumonisins in turkeys. Poult. Sci. 2007, 86, 1887-1893. [CrossRef] [PubMed]

40. Tardieu, D.; Tran, S.T.; Auvergne, A.; Babilé, R.; Benard, G.; Bailly, J.D.; Guerre, P. Effects of fumonisins on liver and kidney sphinganine and the sphinganine to sphingosine ratio during chronic exposure in ducks. Chem. Biol. Interact. 2006, 160, 51-60. [CrossRef]

41. Tran, S.T.; Bailly, J.D.; Tardieu, D.; Durand, S.; Benard, G.; Guerre, P. Sphinganine to sphingosine ratio and predictive biochemical markers of fumonisin B1 exposure in ducks. Chem. Biol. Interact. 2003, 146, 61-72. [CrossRef]

42. Henry, M.H.; Wyatt, R.D.; Fletchert, O.J. The toxicity of purified fumonisin B1 in broiler chicks. Poult. Sci. 2000, 79, 1378-1384. [CrossRef]

43. Tran, S.T.; Tardieu, D.; Auvergne, A.; Bailly, J.D.; Babilé, R.; Durand, S.; Benard, G.; Guerre, P. Serum sphinganine and the sphinganine to sphingosine ratio as a biomarker of dietary fumonisins during chronic exposure in ducks. Chem. Biol. Interact. 2006, 160, 41-50. [CrossRef]

44. Weibking, T.S.; Ledoux, D.R.; Bermudez, A.J.; Turk, J.R.; Rottinghaus, G.E.; Wang, E.; Merrill, A.H. Effects of feeding Fusarium moniliforme culture material, containing known levels of fumonisin B1, on the young broiler chick. Poult. Sci. 1993, 72, 456-466. [CrossRef]

45. ANSES_GuideValidation.pdf. Available online: https:/www.anses.fr/fr/system/files/ANSES_ GuideValidation.pdf (accessed on 19 December 2018).

46. Guibert, E.; Prieur, B.; Cariou, R.; Courant, F.; Antignac, J.P.; Pain, B.; Brillard, J.P.; Froment, P. Effects of mono-(2-ethylhexyl) phthalate (MEHP) on chicken germ cells cultured in vitro. Environ. Sci. Pollut. Res. Int. 2013, 20, 2771-2783. [CrossRef] 
47. Tartarin, P.; Guibert, E.; Touré, A.; Ouiste, C.; Leclerc, J.; Sanz, N.; Brière, S.; Dacheux, J.-L.; Delaleu, B.; McNeilly, J.R.; et al. Inactivation of AMPK $\alpha 1$ Induces Asthenozoospermia and Alters Spermatozoa Morphology. Endocrinology 2012, 153, 3468-3481. [CrossRef]

48. Buege, J.A.; Aust, S.D. Microsomal lipid peroxidation. In Methods in Enzymology; Fleischer, S., Packer, L., Eds.; Biomembranes-Part C: Biological Oxidations; Academic Press: Cambridge, MA, USA, 1978; Volume 52, pp. 302-310.

49. Ohkawa, H.; Ohishi, N.; Yagi, K. Assay for lipid peroxides in animal tissues by thiobarbituric acid reaction. Anal. Biochem. 1979, 95, 351-358. [CrossRef]

50. Yagi, K. Lipid peroxides and human diseases. Chem. Phys. Lipids 1987, 45, 337-351. [CrossRef]

51. Hochereau-de Reviers, M.T.; Perreau, C.; Pisselet, C.; Fontaine, I.; Monet-Kuntz, C. Comparisons of endocrinological and testis parameters in 18-month-old Ile de France and Romanov rams. Domest. Anim. Endocrinol. 1990, 7, 63-73. [CrossRef]

(C) 2019 by the authors. Licensee MDPI, Basel, Switzerland. This article is an open access article distributed under the terms and conditions of the Creative Commons Attribution (CC BY) license (http://creativecommons.org/licenses/by/4.0/). 